\title{
Effects of denervation and muscle ablation procedures on the canine pharyngo-oesophageal junction ${ }^{1}$
}

\author{
VINCENT P. LYNCH, JERRY F. SCHLEGEL, and \\ F. HENRY ELLIS, JR.
}

Mayo Clinic and Mayo Foundation, Rochester, Minnesota, USA

\begin{abstract}
The resting and deglutitive pressures in the pharynx, pharyngo-oesophageal sphincter, and upper oesophagus were obtained from 32 healthy intact dogs. The dogs were divided into groups and submitted to either bilateral denervation or muscle ablation. Manometric studies were repeated two weeks and four weeks after operation. Bilateral division of the pharyngo-oesophageal nerve reduced the resting sphincteric pressure and the amplitude of the pressures of sphincteric relaxation and contraction after deglutition. Bilateral division of the recurrent laryngeal nerves or bilateral division of the cervical sympathetic trunks did not alter sphincteric resting or deglutition pressures. Muscle ablation involving the cricopharyngeus muscle reduced resting sphincteric pressure, shortened the zone of elevated pressure, and decreased the amplitude of the pressure responses to deglutition. These findings confirm that the cricopharyngeus muscle is the upper oesophageal sphincter and that it receives its motor innervation from the pharyngo-oesophageal nerve, a branch of the pharyngeal plexus that comes primarily from the vagus nerve.
\end{abstract}

The anatomy and physiology of the pharyngooesophageal region has not been as well studied as that of the body of the oesophagus and its lower sphincter, in either man or the dog. Controversy exists as to the precise location of the upper sphincter and its nerve supply. Morphologically, the sphincter has been described as the lower portion of the inferior constrictor of the pharynx (Birmingham, 1898; Abel, 1913; Doty and Bosma, 1956 ; Dyce, 1957), as a specialized band of muscle in the junctional zone (Blakeley, Garety, and Smith, 1968), and as the upper transverse fibres of the oesophagus (Lerche, 1950). Previous investigators have stated that the motor innervation to the region was vagal via branches of the pharyngeal plexus (Levitt, Dedo, and Ogura, 1965; Lund, 1965) or via branches of the recurrent laryngeal nerves (Terracol, 1938) or both (Hwang, Grossman, and Ivy, 1948). Other investigators have stated that the sympathetic nerves provided motor innervation to the pharyngooesophageal sphincter, causing it to contract, whereas the autonomic vagal fibres caused the sphincter to relax (Blakeley et al., 1968).

The purpose of this study was to define the limits of the canine pharyngo-oesophageal sphincter and to determine the effects of certain dener-

1This investigation was supported in part by Research Grant AM2015 from the National Institutes of Health. Public Health Service vation and muscle ablation procedures on the function of the pharynx, pharyngo-oesophageal sphincter, and oesophagus.

\section{METHODS AND PROCEDURES}

PRELIMINARY INVESTIGATIONS Necropsies were performed on six dogs and confirmed the presence of a pharyngeal branch of the vagus that is either a direct offshoot of the parent vagal nerve above the nodose ganglion or arises from the beginning of the pharyngeal nerve. This nerve was described by Reid in 1838 and subsequently has been given various names (Hwang et al., 1948; Levitt et al., 1965; Lund, 1965). In this report we shall call it the 'pharyngo-oesophageal nerve'. The pharyngo-oesophageal nerve travels across the ventral surface of the superior cervical sympathetic ganglion to which it is firmly attached by fibrous bands and from which it receives a branch. It then continues caudally, closely applied to the pharyngeal wall dorsal to al of the other nerves supplying the pharynx, ending in many fine branches on the surface of the cricopharyngeus and the upper oesophagus.

In six other dogs, the pharyngo-oesophageal nerve and other nerves supplying the pharynx and upper oesophagus were stimulated electrically during acute experiments. The dogs were anaesthetized with pentobarbital, $25 \mathrm{mg} / \mathrm{kg}$ intravenously, and the pharynx and cervical oesophagus were exposed through a long midline incision. The nerves were then stimulated systematically using bipolar electrodes. 
The stimulations were square-wave pulses at a rate of $1 \mathrm{pulse} / \mathrm{sec}$, with a duration of $0.2 \mathrm{msec}$. Voltage was increased until a response occurred. The external surface of the pharynx, pharyngo-oesophageal junction, and oesophagus was observed directly, and the inner structures were observed endoscopically. The following responses were obtained.

\section{Nerve stimulated}

Pharyngo-oesophageal

Pharyngeal branches of vagus

Vagus, below nodose ganglion

External laryngeal

\section{Recurrent laryngeal}

\section{Internal laryngeal \\ Superior cervical sympathetic ganglion \\ Cervical sympathetic trunk}

aNimals Thirty-two healthy adult mongrel dogs, ranging in weight from 10 to $14 \mathrm{~kg}$, were used. The dogs were trained to lie quietly during oesophageal motility studies; anaesthesia was not used.

PRESSURE DETERMINATION Oesophageal motility tests were performed on all dogs before any operative procedure and two and eight weeks after the procedure, by methods described previously (Schlegel and Code, 1958; Greenwood, Schlegel, Code, and Ellis, 1962). Two open-tip tubes (OT) and one balloon-covered open-tip tube (BT) were used as pressure detectors. The detecting units were spaced $3 \mathrm{~cm}$ apart, with the balloon always the most distal. Resting and deglutition pressures were obtained at each $0.5-\mathrm{cm}$ interval in the upper oesophagus, the pharyngo-oesophageal sphincter, and the pharynx. Swallowing was induced by the injection of 0.5 to $1.0 \mathrm{ml}$ of water into the back of the mouth.

ANALYSIS OF RECORDS Maximal resting sphincteric pressures were measured and are expressed in $\mathrm{cm}$ $\mathrm{H}_{2} \mathrm{O}$ in relation to resting upper oesophageal pressure. The deglutition responses of the pharyngooesophageal sphincter are expressed in $\mathrm{cm} \mathrm{H}_{2} \mathrm{O}$ in relation to the resting pressure of the sphincter. The changes in pressure and in the length of the pharyngo-oesophageal pressure between preoperative and postoperative records were tested statistically by application of Student's $t$ test (Fisher, 1946).
OPERATIVE PROCEDURES Surgical procedures were performed with the usual aseptic surgical precautions. The dogs were anaesthetized with intravenously administered pentobarbital, $25 \mathrm{mg} / \mathrm{kg}$ body weight, intubated, and ventilated with room air and nitrous oxide. All procedures were carried out via a longitudinal midline cervical incision.

DENERVATION Bilateral division of the pharyngooesophageal nerves was done on six dogs. The strap muscles were mobilized and retracted medially and the carotid vessels laterally, exposing the constrictor muscle of the pharynx. The pharyngo-oesophageal nerve was identified and stimulated electrically to confirm that contraction of the cricopharyngeus muscle and upper oesophagus occurred. Bilateral resection of $1 \mathrm{~cm}$ of each nerve was performed cephalad to the cricopharyngeus muscle (Fig. 1).

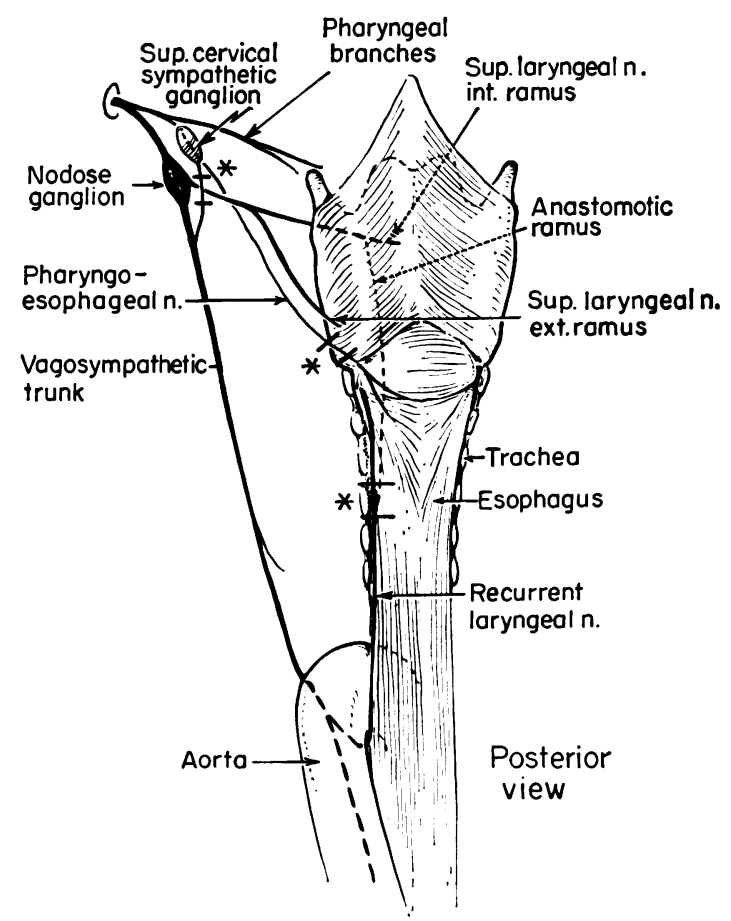

FIG. 1. Diagrammatic representation of posterior aspect of vagal and sympathetic nerve supply to pharynx and upper oesophagus of the dog. Sympathetic fibres to head and neck join the vagus to form the vasosympathetic trunk and leave the vagus caudal to the nodose ganglion to form the superior cervical sympathetic ganglion. Note that pharyngo-oesophageal nerve runs across the ventral surface of superior cervical sympathetic ganglion to which it is firmly attached by fibrous bands. Asterisks indicate sites at which various nerve resections were performed. 
Recurrent laryngeal nerve resections were done on four dogs. The strap muscles were mobilized on both sides and retracted laterally with the thyroid glands, exposing the recurrent and pararecurrent laryngeal nerves on the sides of the oesophagus behind the trachea. The nerves were stimulated electrically, and the corresponding vocal cord twitch was observed endoscopically. One centimetre of each of the nerves was resected (Fig. 1).

Six dogs underwent bilateral division of the cervical sympathetic trunks. The strap muscles were mobilized on both sides and retracted medially. The carotid sheaths were identified and split longitudinally; this exposed the vagosympathetic trunks. The sympathetic component was identified, and $1 \mathrm{~cm}$ of it was resected bilaterally (Fig. 1).

MUSCLE ABLATION Myotomy of the cricopharyngeus muscle and oesophagus was performed on four dogs. The left recurrent laryngeal nerve was identified where it disappeared beneath the cricopharyngeus muscle; this localizes the caudal border of the muscle. The dorsal wall of the lower pharynx and the upper oesophagus was exposed by blunt dissection and retraction. A small posterior midline incision was made across the cricopharyngeus muscle and was extended $2 \mathrm{~cm}$ caudal to its lower edge. The incision was deepened to the mucosa, and the muscle was separated with forceps from the underlying mucosa for approximately half the circumference of the oesophagus and a similar distance of the lower pharynx beneath the cricopharyngeus muscle. A myotomy, $3.2 \mathrm{~cm}$ long, was then performed on the undermined muscle (Fig. 2). Profuse bleeding always occurred from a plexus of small veins beneath the cricopharyngeus muscle. The bleeding points were coagulated with diathermy.

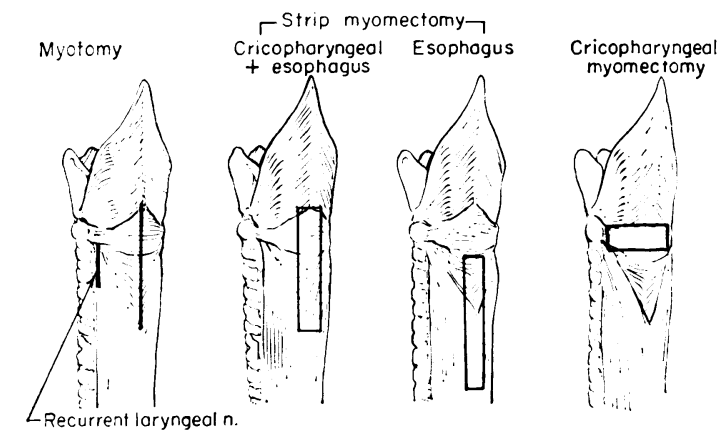

FIG. 2. Diagrammatic representation of muscle ablation procedures.

Strip myomectomy of the cricopharyngeus muscle and oesophagus was carried out on five dogs. This was performed in a similar manner; however, the oesophageal muscle lateral to the excised portion was not undermined. The excised strip of muscle was $0.75 \mathrm{~cm}$ wide and $3.2 \mathrm{~cm}$ long (Fig. 2).
Three dogs underwent strip myomectomy of the oesophagus. A strip of muscle, $3.2 \mathrm{~cm}$ long and 0.75 $\mathrm{cm}$ wide, was excised from the posterior oesophagus caudal to the margin of the cricopharyngeus muscle (Fig. 2).

Myomectomy of the cricopharyngeus muscle was done on four dogs. The surgical approach differed from the other muscle ablative procedures in that the pharyngo-oesophageal region was exposed on both sides. The recurrent laryngeal nerves were identified and traced to the caudal margin of the cricopharyngeus muscle. Here there was a plane of cleavage between the cricopharyngeus muscle and the oesophagus laterally. However, in the midline posteriorly, the cricopharyngeus muscle and the upper circular fibres of the oesophagus are continuous and can be separated only by sharp dissection. Since at operation the upper margin of the cricopharyngeus muscle is indistinct from the remainder of the inferior constrictor muscle, the lower $1.2 \mathrm{~cm}$ of the inferior constrictor muscle was designated cricopharyngeus muscle. After the planes of cleavage had been opened on both lateral aspects of the upper oesophagus, a Kocker forceps was applied to the cricopharyngeus muscle and the muscle was dissected from the cricoid cartilage laterally. The same procedure was then carried out on the other side. Care was taken to avoid injury to the recurrent laryngeal nerves. However, damage to the pharyngo-oesophageal nerve could not be avoided. A band of muscle, $1.2 \mathrm{~cm}$ wide and $6 \mathrm{~cm}$ long, was removed by dividing it from the thyropharyngeus muscle cranially and the circular muscle fibres of the oesophagus caudally (Fig. 2). The resulting denuded area was much larger owing to the retraction of the muscle above and below.

\section{RESULTS}

DENERVATION PROCEDURES The dogs recovered quickly after the operation, and no special treatment or diet was required. No dysphagia was noted. The four dogs that had bilateral division of the recurrent laryngeal nerves were unable to bark. The six dogs with bilateral division of the cervical sympathetic trunks had bilateral Horner's syndrome.

Bilateral division of PHARYNGo-oesophageal NERVES A significant reduction in the resting pressures occurred after division of the pharyngooesophageal nerves (Fig. 3, Table I). A small reduction in the length of the sphincter occurred. $\stackrel{5}{+}$ By open-tip detection the sphincter was $1.5 \mathrm{~cm}$. in length before surgery and $1.3 \mathrm{~cm}$ after surgery. The region was reduced from $2.3 \mathrm{~cm}$ preoperatively to $1.9 \mathrm{~cm}$ postoperatively by balloon detection. The differences were not significant. The relaxation of the sphincter was not significantly 


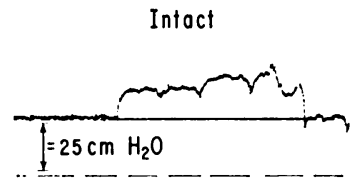

Pharyngo-esophogeal nerve
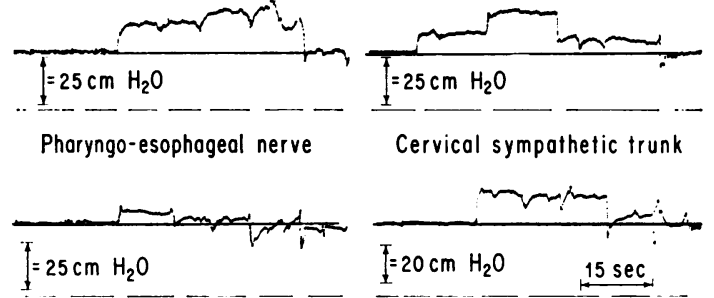

Cervical sympathetic trunk

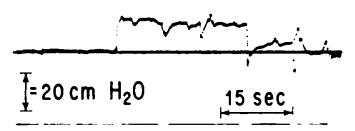

FIG. 3. Resting-pressure profiles of pharyngo-oesophageal junction by open-tip tube detectors before and after bilateral denervation. Unit was withdrawn $0.5 \mathrm{~cm}$ at each break in base line from the oesophagus, on the left-hand portion of each panel, through pharyngo-oesophageal sphincter into pharynx. Note significant reduction of pressure after pharyngo-oesophageal nerve section.

\section{T A B LE I}

DENERVATION PROCEDURES AND MEAN ( \pm SE) MAXIMAL RESTING PRESSURES AT CANINE PHARYNGOOESOPHAGEAL SPHINCTER ${ }^{1}$

\begin{tabular}{c|c|c|c|c}
\hline & \multirow{2}{*}{\begin{tabular}{c} 
No. \\
of \\
\cline { 3 - 5 }
\end{tabular}} & Dogs & Procedure & \multicolumn{3}{|c}{ Open-tip tube } \\
\hline $\begin{array}{c}\text { Bilateral division } \\
\text { of pharyngo- } \\
\text { oesophageal nerve }\end{array}$ & 6 & $22 \cdot 7 \pm 1 \cdot 1$ & $14 \cdot 6 \pm 1 \cdot 3^{2}$ & $10 \cdot 2 \pm 2 \cdot 4^{2}$ \\
$\begin{array}{c}\text { Bilateral division } \\
\text { of recurrent } \\
\text { laryngeal nerves } \\
\begin{array}{c}\text { Bilateral division } \\
\text { of cervical } \\
\text { sympathetic } \\
\text { trunks }\end{array}\end{array}$ & 6 & $19 \cdot 5 \pm 1 \cdot 5$ & $21 \cdot 9 \pm 1 \cdot 5$ & $19 \cdot 2 \pm 1 \cdot 3$ \\
\hline
\end{tabular}

'Pressures in $\mathrm{cm} \mathrm{H}_{2} \mathrm{O}$ related to upper oesophageal pressure

'Significantly different from preoperative (control) value $(P<0.01)$

altered by this denervation (Fig. 4, Table II). Contractions of the sphincter and upper oesophagus, however, were affected. The amplitude of sphincteric contraction was reduced to $39 \%$ of the preoperative value (Fig. 4, Table II).

\begin{tabular}{|c|c|c|c|}
\hline Intoct & $\begin{array}{c}\text { Phoryngo- } \\
\text { esophageal } \\
\text { nerve }\end{array}$ & $\begin{array}{l}\text { Recurrent } \\
\text { loryngeal } \\
\text { nerve }\end{array}$ & $\begin{array}{c}\text { Cervical } \\
\text { sympothetic } \\
\text { trunk }\end{array}$ \\
\hline
\end{tabular}
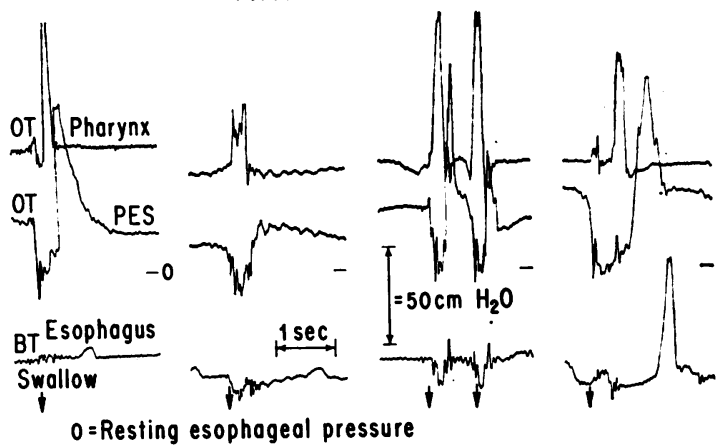

FIG. 4. Deglutition responses in pharynx, pharyngooesophageal sphincter (PES), and oesophagus in an intact dog and in dogs after bilateral denervation, with open-tip $(O T)$ and balloon-tip $(B T)$ detectors. Note reduction in amplitude of pharyngeal and sphincteric contraction pressures after pharyngo-oesophageal nerve section.

Oesophageal peristalsis was first detected from $1.5 \mathrm{~cm}$ to $10 \mathrm{~cm}$ (mean of $5 \mathrm{~cm}$ ) distal to its occurrence preoperatively.

OTHER DENERVATION PROCEDURES Neither the resting pressures nor the responses to deglutition were altered by division of the laryngeal nerves or the cervical sympathetic trunks (Figs. 2 and 3, Tables I and II).

MUSCle ABLATION PROCEDURES The four dogs subjected to myotomy of the cricopharyngeus muscle had minimal dysphagia immediately after surgery. However, all dogs that underwent muscle ablation ate the normal kennel diet, remained healthy, and maintained their preoperative weight.

MYOTOMY OF CRICOPHARYNGEUS MUSCLE AND OESOPHAGUS A significant reduction in the rest-

T A B LE II

DENERVATION PROCEDURES AND MEAN ( \pm SE) MAXIMAL DEGLUTITION PRESSURE (OPEN-TIP TUBE DETECTION') AT CANINE PHAR YNGO-OESOPHAGEAL SPHINCTER

\begin{tabular}{|c|c|c|c|c|c|c|c|}
\hline \multirow{3}{*}{ Procedure } & \multirow{3}{*}{$\begin{array}{c}\text { No. } \\
\text { of } \\
\text { Dogs }\end{array}$} & \multicolumn{3}{|c|}{ Relaxation } & \multicolumn{3}{|c|}{ Contraction } \\
\hline & & \multirow{2}{*}{ Preoperative } & \multicolumn{2}{|c|}{ Postoperative } & \multirow{2}{*}{ Preoperative } & \multicolumn{2}{|c|}{ Postoperative } \\
\hline & & & 2 weeks & 8 weeks & & 2 weeks & 8 weeks \\
\hline Bilateral division of pharyngo- & 6 & $-25 \cdot 6 \pm 3 \cdot 4$ & $-19 \cdot 2 \pm 3 \cdot 0$ & $-21 \cdot 8 \pm 3 \cdot 6$ & $42 \cdot 8 \pm 6 \cdot 5$ & $16 \cdot 7 \pm 6 \cdot 2^{2}$ & $16 \cdot 5 \pm 4 \cdot 1^{2}$ \\
\hline $\begin{array}{l}\text { Bilateral division of recurrent laryngeal } \\
\text { nerves }\end{array}$ & 4 & $-18 \cdot 0 \pm 1 \cdot 6$ & $-18 \cdot 5 \pm 4 \cdot 3$ & $-16 \cdot 0 \pm 3 \cdot 2$ & $43 \cdot 3 \pm 6 \cdot 0$ & $30 \cdot 1 \pm 3 \cdot 5$ & $40 \cdot 0 \pm 3 \cdot 5$ \\
\hline $\begin{array}{l}\text { Bilateral division of cervical sympathetic } \\
\text { trunks }\end{array}$ & 6 & $-19 \cdot 0 \pm 3 \cdot 0$ & $-21 \cdot 8 \pm 3 \cdot 3$ & $-22 \cdot 2 \pm 1 \cdot 5$ & $46 \cdot 4 \pm 5 \cdot 3$ & $46 \cdot 2 \pm 3 \cdot 9$ & $45 \cdot 3 \pm 5 \cdot 3$ \\
\hline
\end{tabular}

${ }^{1}$ Pressures in $\mathrm{cm}_{2} \mathrm{O}$ as related to resting sphincter pressure

'Significantly different from preoperative (control) value $(P<0.01)$ 
ing pressures of the pharyngo-oesophageal sphincter was noted after this operation (Fig. 5, Table III). The length of the zone of elevated pressure was also significantly reduced $(\mathbf{P}<005)$.

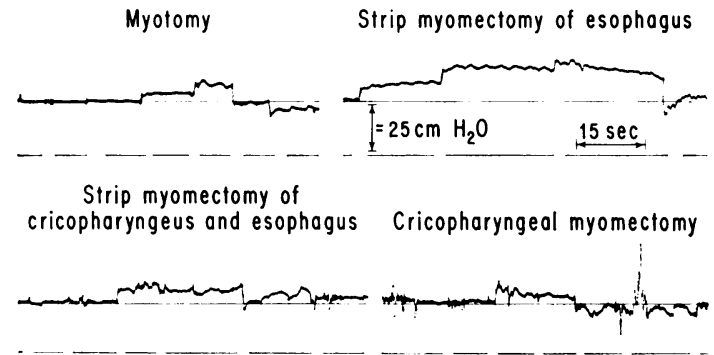

FIG. 5. Resting-pressure profiles of pharyngo-oesophageal junction by open-tip detectors 8 weeks after muscle ablation. Unit was withdrawn (on the left) from oesophagus into pharynx and (on the right) $0.5 \mathrm{~cm}$ at each break in the base line. Note depression of pressure after all procedures involving the cricopharyngeus muscle.

T A B L E I I I

MUSCLE ABLATION PROCEDURES AND MEAN ( \pm SE) MAXIMAL RESTING PRESSURE AT CANINE PHARYNGOOESOPHAGEAL SPHINCTER ${ }^{1}$

\begin{tabular}{|c|c|c|c|c|}
\hline \multirow{3}{*}{ Procedure } & \multirow{3}{*}{$\begin{array}{c}\text { No. } \\
\text { of } \\
\text { Dogs }\end{array}$} & \multicolumn{3}{|c|}{ Open-tip Tube } \\
\hline & & \multirow{2}{*}{ Preoperative } & \multicolumn{2}{|c|}{ Postoperative } \\
\hline & & & 2 weeks & 8 weeks \\
\hline $\begin{array}{l}\text { Myotomy of } \\
\text { cricopharyngeus } \\
\text { and upper } 2 \mathrm{~cm} \text { of } \\
\text { oesophagus }\end{array}$ & 4 & $21 \cdot 9 \pm 2 \cdot 2$ & $\overline{12 \cdot 2 \pm 1 \cdot 1^{2}}$ & $\overline{14 \cdot 4 \pm 1 \cdot 7^{2}}$ \\
\hline $\begin{array}{l}\text { Strip myomectomy } \\
\text { of cricopharyngeus } \\
\text { and upper } 2 \mathrm{~cm} \text { of } \\
\text { oesophagus }\end{array}$ & 5 & $21 \cdot 8: 2 \cdot 0$ & $12 \cdot 7 \pm 4 \cdot 5$ & $9 \cdot 7 \pm 1 \cdot 4^{3}$ \\
\hline $\begin{array}{l}\text { Strip myomectomy } \\
\text { of upper } 3 \cdot 2 \mathrm{~cm} \\
\text { of oesophagus }\end{array}$ & 3 & $19 \cdot 8 \pm 2 \cdot 5$ & $14 \cdot 8 \pm 3 \cdot 6$ & $16 \cdot 0 \pm 3 \cdot 4$ \\
\hline $\begin{array}{l}\text { Cricopharyngeal } \\
\text { myomectomy }\end{array}$ & 4 & $20 \cdot 2 \div 1 \cdot 7$ & $12 \cdot 3 \pm 3 \cdot 8$ & $8 \cdot 8 \pm 1 \cdot 7^{3}$ \\
\hline
\end{tabular}

${ }^{1}$ Pressure in $\mathrm{Cm} \mathrm{H}_{2} \mathrm{O}$ related to upper oesophageal pressure

Significantly different from preoperative (control) value: ${ }^{2} \mathrm{P}<0.05$; s $P<0.01$.
By OT determination, the preoperative length was $1.9 \mathrm{~cm}$ and at 8 weeks postoperatively, $1 \mathrm{~cm}$. The corresponding values by BT determination were $2.4 \mathrm{~cm}$ and $1.6 \mathrm{~cm}$. The amplitude of sphincteric relaxation was reduced, but the differences were not significant (Fig. 6, Table IV). The amplitude of the contraction of the sphincter was significantly reduced from the preoperative values (Fig. 6, Table IV).

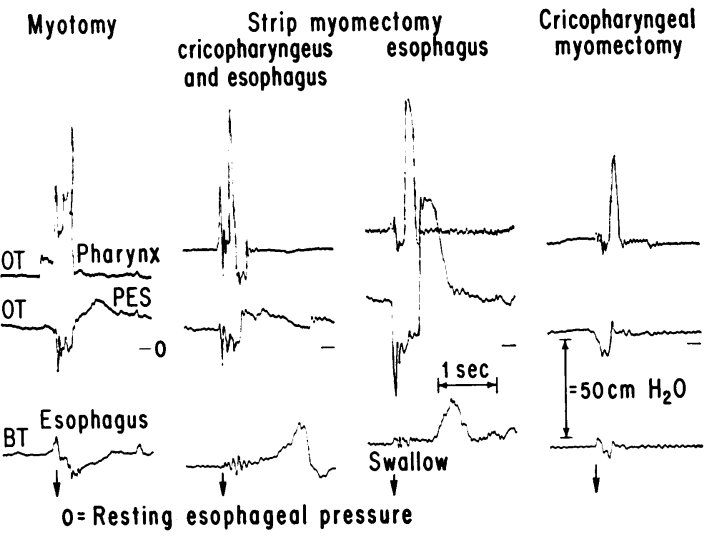

FIG. 6. Deglutition responses in pharynx, pharyngooesophageal sphincter (PES), and oesophagus after muscle ablation. Note that muscle ablation involving cricopharyngeus muscle caused diminution of amplitude of sphincteric contraction.

STRIP MYOMECTOMY OF CRICOPHARYNGEUS MUSCLE AND UPPER OESOPHAGUS The resting sphincteric pressure was reduced from the preoperative value of $21.8 \mathrm{~cm} \mathrm{H}_{2} \mathrm{O}$ to $12.7 \mathrm{~cm} \mathrm{H}_{2} \mathrm{O}$ at 2 weeks and to $9.7 \mathrm{~cm} \mathrm{H}_{2} \mathrm{O}$ at 8 weeks. Only the 8 -week value was statistically significant (Fig. 5, Table III). A significant $(P<0.05)$ shortening of the zone of elevated pressure was noted by OT detection, from $1.9 \mathrm{~cm}$ preoperatively to $1.1 \mathrm{~cm} 8$ weeks postoperatively. A reduction also was apparent by

T A B LE IV

MUSCLE ABLATION PROCEDURES AND MEAN ( \pm SE) MAXIMAL DEGLUTITION PRESSURE (OPEN-TIP TUBE DETECTION') AT CANINE PHARYNGO-OESOPHAGEAL SPHINCTER

\begin{tabular}{|c|c|c|c|c|c|c|c|}
\hline \multirow{3}{*}{ Procedure } & \multirow{3}{*}{$\begin{array}{l}\text { No. } \\
\text { of } \\
\text { Dogs }\end{array}$} & \multicolumn{3}{|c|}{ Relaxation } & \multicolumn{3}{|c|}{ Contraction } \\
\hline & & \multirow{2}{*}{ Preoperative } & \multicolumn{2}{|c|}{ Postoperative } & \multirow{2}{*}{ Preoperative } & \multicolumn{2}{|c|}{ Postoperative } \\
\hline & & & 2 weeks & 8 weeks & & 2 weeks & 8 weeks \\
\hline Myotomy of cricopharyngeus and upper & 4 & $-26 \cdot 8 \pm 5 \cdot 2$ & $-15 \cdot 7 \pm 3 \cdot 2$ & $-21 \cdot 2 \pm 3 \cdot 6$ & $38 \cdot 7 \pm 4 \cdot 3$ & $13 \cdot 8 \pm 2 \cdot 8^{2}$ & $22 \cdot 5 \pm 1 \cdot 0^{2}$ \\
\hline $\begin{array}{l}2 \mathrm{~cm} \text { of oesophagus } \\
\text { Strip myomectomy of cricopharyngeus and }\end{array}$ & 5 & $-25 \cdot 3 \pm 3 \cdot 4$ & $-17 \cdot 2 \pm 1 \cdot 4$ & $-15 \cdot 5 \pm 2 \cdot 7$ & $43 \cdot 4 \pm 5 \cdot 8$ & $12 \cdot 2 \pm 3 \cdot 1^{2}$ & $6 \cdot 9 \pm 1 \cdot 8^{3}$ \\
\hline $\begin{array}{l}\text { upper } 2 \mathrm{~cm} \text { of oesophagus } \\
\text { Strip myomectomy of upper } 3.2 \mathrm{~cm} \text { of }\end{array}$ & 3 & $-19 \cdot 0 \pm 1 \cdot 4$ & $-19 \cdot 7 \pm 4 \cdot 2$ & $-22 \cdot 8 \pm 2 \cdot 6$ & $36 \cdot 9 \pm 6 \cdot 0$ & $40 \cdot 0 \pm 15 \cdot 3$ & $34 \cdot 9 \pm 2 \cdot 6$ \\
\hline $\begin{array}{l}\text { oesophagus } \\
\text { Cricopharyngeal myomectomy }\end{array}$ & 4 & $-20.9 \pm 1 \cdot 8$ & $-11 \cdot 7 \pm 3 \cdot 6$ & $-7.9 \pm 1.5^{2}$ & $44 \cdot 2 \pm 5 \cdot 5$ & $0.7 \pm 0.7^{3}$ & $0.0 \pm 0.0^{3}$ \\
\hline
\end{tabular}

1 Pressures in $\mathrm{cm} \mathrm{H}_{2} \mathrm{O}$ as related to resting sphincter pressure

Significantly different from preoperative (control) value: ${ }^{2} \mathrm{P}<0.05$; ${ }^{3} \mathrm{P}<0.01$ 
balloon detection, from $2.2 \mathrm{~cm}$ to $1.7 \mathrm{~cm}$, but this was not significant. Relaxation of the sphincter was not significantly altered (Fig. 6, Table IV). Contraction of the sphincter was reduced to about $15 \%$ of the preoperative value 8 weeks after this operation (Fig. 6, Table IV).

STRIP MYOMECTOMY OF OESOPHAGUS No significant alterations were observed in any of the dogs after this procedure (Figs 5 and 6, Tables III and IV).

CRICOPHARYNGEAL MYOMECTOMY Resting pressures were reduced, but the differences between preoperative and postoperative values were significant only at 8 weeks (Fig. 5, Table III). The length of the zone of elevated pressure was shortened significantly measured by both types of pressure detectors $(P<0.05)$. The amplitudes of both relaxation and contraction of the sphincter were reduced after this procedure (Fig. 6, Table IV). No contractions were detected 8 weeks postoperatively. Oesophageal peristalsis was eliminated in the upper oesophagus to the same extent as was observed in the dogs that had division of the pharyngo-oesophageal nerves. No recovery was noted 8 weeks after operation.

\section{COMMENT}

There is universal agreement that a sphincter exists at the pharyngo-oesophageal junction. The muscle in this region was designated as a separate entity and named the 'cricopharyngeus muscle' by Valsalva in 1704. Birmingham (1898) made the first classic anatomical study of the region in man and stated that the cricopharyngeus muscle was the lower portion of the inferior constrictor muscle; succeeding anatomists have generally agreed with him (Abel, 1913; Batson, 1955; Doty and Bosma, 1956 ; Dyce, 1957).

Physiologically, the region functions as a sphincter. Fyke and Code (1955), using manometry and simultaneous radiography in humans, found that a zone of maximal pressure was located behind the cricoid cartilage. In 1958, Schlegel and Code demonstrated a similar sphincteric zone in the pharyngo-oesophageal region in the dog.

Electromyographic studies have detected spontaneous discharges from the cricopharyngeus muscle that were greater than those obtained from the pharynx and the oesophagus, indicating that in the resting state the cricopharyngeus muscle is more active than the surrounding muscle
(Andrew, 1956 ; Doty and Bosma, 1956 ; Levitt et al., 1965).

The cervical vagus nerve is complex. It contains four groups of fibres: the special visceral afferent and efferent fibres that supply the pharynx and the upper cervical oesophagus; these are somatic fibres and synapse in the jugular ganglion and the nucleus ambiguus, respectively (Kuntz, 1945). The pharyngo-oesophageal nerve is thus a somatic nerve ; this is confirmed by the fact that there are no ganglia or Auerbach's plexus in the cricopharyngeus muscle. The remainder of the vagus nerve, the general visceral afferent fibres, and the general visceral efferent fibres are part of the autonomic nervous system. These fibres supply all the viscera. The efferent fibres arise in the dorsal nucleus of the vagus going to the gastrointestinal tract and end in the myenteric plexus where they synapse with the ganglia of the thirdorder motor neurons. The afferent fibres synapse in the nodose ganglion.

Further confusion has arisen because in the dog, the animal in which most of the experimental work has been done, the sympathetic nerves to the head and neck unite to form the vagosympathetic trunk (Kiss, 1931 ; Mizeres, 1955). Below the nodose ganglion, the sympathetic fibres leave the trunk to form the superior cervical sympathetic ganglion from which arise the fibres that supply the pharyngo-oesophageal region. The pharyngo-oesophageal nerve is firmly adherent to the superior cervical ganglion by fibrous bands. This may explain why Kuré et al. (1928-29) found that, when the superior cervical sympathetic ganglion was extirpated, stasis of barium in the upper oesophagus was observed radiographically. Damage to the pharyngo-oesophageal nerve may have occurred during the surgery they performed. Paralysis of the upper oesophagus would result and stasis of barium then could occur.

Our results clearly show that the pharyngooesophageal nerve is the motor nerve to the sphincter in the dog. Stimulation of this nerve causes the sphincter to contract; bilateral division causes diminution of both resting and deglutition sphincter pressures. These findings agree with those of Lund (1965), who used nerve stimulation and simultaneous manometry in anaesthetized dogs, but differ from those of Kirchner (1958), who claimed that stimulation of the sympathetic nerve supply causes the upper sphincter to contract, whereas stimulation of the vagus causes relaxation.

Experiments on recurrent laryngeal and sympathetic nerve stimulation had no effect on the 
function of the sphincter or the upper oesophagus, and no changes were noted manometrically after division of the nerves. Hwang (1953) found that total thoracic sympathectomy had no effect on the oesophagus of the dog. With stimulation of the recurrent laryngeal nerves, contractions occurred in the lower quarter of the cervical oesophagus in one-fifth of the dogs that Hwang (1953) studied.

The manometric results in our study clearly reveal that the cricopharyngeus muscle is the sphincter. Myotomy and strip myomectomy that involved the cricopharyngeus muscle caused reduction in both the resting and the deglutition pressures. Strip myomectomy of the oesophagus below the cricopharyngeus muscle did not signifcantly alter the resting or deglutitory pressures, indicating that oesophageal muscle caudad to the cricopharyngeus muscle is not sphincteric.

Lund (1965) has stated that bilateral myotomy or detachment of one cricopharyngeus muscle was required to abolish the normal resting sphincter pressure in dogs. In the present study, muscle ablation involving the cricopharyngeus muscle caused a significant reduction in resting sphincter pressure; however, not even cricopharyngeal myomectomy completely abolished the resting pressure zone. Cricopharyngeal myomectomy, however, abolished sphincteric contractions after deglutition. The reduction in amplitude of sphincteric relaxation in our study is directly related to the reduction in the resting sphincter pressure.

Peristalsis was eliminated for 1.5 to $10 \mathrm{~cm}$ in the upper oesophagus in the dogs that underwent cricopharyngeal myomectomy and in the dogs that underwent bilateral resection of the pharyngo-oesophageal nerve. Damage to this nerve occurred during myomestomy. Recovery of peristalsis did not occur in eight weeks, as observed manometrically. Hwang (1953) studied dogs radiographically after division of the pharyngo-oesophageal nerve and noted the return of peristalsis within one month. He attributed the recovery to the recurrent laryngeal nerves being activated to function. The results of our study do not support this, and the difference may be due to a more accurate method of detecting peristalsis.

\section{REFERENCES}

Abel, W. (1913). The arrangement of the longitudinal and circular musculature at the upper end of the oesophagus. J. Anat. Physiol. (Lond.), 47, 381.

Andrew, B. L. (1956). The nervous control of the cervical oesophagus of the rat during swallowing. J. Physiol. (Lond.), 134, 729. Batson, O. V. (1955). The cricopharyngeus muscle. Ann. Otol
(St. Louis), 64, 47.

Birmingham, A. (1898). A study of the arrangement of the muscular fibres at the upper end of the oesophagus J. Anat. Physiol. (Lond.), 33, 10.

Blakeley, W. R., Garety, E. J., and Smith, D. E. (1968) Section of the cricopharyngeus muscle for dysphagia ws Arch. Surg., 96, 745.

Doty, R. W., and Bosma, J. F. (1956). An electromyographic analysis of reflex deglutition. $J$. Neurophysiol., 19, 44.ت

Dyce, K. M."(1957). The muscles of the pharynx and palateon of the dog. Anat. Rec., 127, 497.

Fisher, R. A. (1946). Statistical Methods for Research Workers, 10th ed. Oliver and Boyd, Edinburgh and London.

Fyke, F. E., Jr., and Code, C. F. (1955). Resting and degluti tion pressures in the pharyngo-esophageal region. $\infty$ Gastroenterology, 29, 24.

Greenwood, R. K., Schlegel, J. F., Code, C. F., and Ellis, F. H., Jr. (1962). The effect of sympathectomy, vagotomy and oesophageal interruption on the canine gastrooesophageal sphincter. Thorax, 17, 210.

Hwang, K. (1953). Mechanism of the functional recovery of the cervical portion of the esophagus after bilaterake resection of the pharyngoesophageal nerve in the $\operatorname{dog}_{\omega}$ Amer. J. Physiol., 174, 231.

—, Grossman, M. I., and Ivy, A. C. (1948). Nervous control of the cervical portion of the esophagus. Amer J. Physiol., 154, 343.

Kirchner, J. A. (1958). The motor activity of the cricon pharyngeus muscle. Laryngoscope (St. Louis), 68, 1119 요

Kiss, F. (1931). The relationship between vagus and sympa thetic in the vertebrates. J. Anat. (Lond.), 66, 153.

Kuntz, A. (1945). The Autonomic Nervous System, 3rd. ed? Lea and Febiger, Philadelphia.

Kuré, K., Fujii, N., Kawaguzi, K., Shiba, T., and Nitta, Y: (1928-29). Experimentelles Studium über die Innervation des Oesophagus. Pflügers Arch. ges. Physiol. 221, 367.

Lerche, W. (1950). The Esophagus and Pharynx in Action $A$ Study of Structure in relation to Function. Thomaso Springfield, Illinois.

Levitt, M. N., Dedo, H. H., and Ogura, J. H. (1965). Thळ cricopharyngeus muscle, an electromyographic study in the dog. Laryngoscope (St. Louis), 75, 122.

Lund, W. S. (1965). A study of the cricopharyngeal sphinc? ter in man and in the dog. Ann. roy. Coll. Surg. Engl $\frac{D}{2}$ 37, 225.

Mizeres, N. J. (1955). The anatomy of the autonomic nervous system in the dog. Amer. J. Anat., 96, 285.

Reid, J. (1838). An experimental investigation into the functions of the eighth pair of nerves, or the glossof pharyngeal, pneumogastric, and spinal accessory $\underbrace{\omega}$
Edinb. med. Surg. J., 49, 109.

Schlegel, J. F., and Code, C. F. (1958). Pressure charactero istics of the esophagus and its sphincters in dogs. Amer. $J \frac{\complement}{\mathbb{D}}$ Physiol., 193, 9.

Terracol, J. (1938). Les Maladies de l'Oesophage. Masson eto Cie, Paris.

Valsalva, A. M. (1704). De aure humana tractatus, in quäD integra ejusdem auris fabrica, multis novis inventis, eQ iconismis illustrata, describitur; omniumque eius partiung usus indagantur. Quibus interposita est musculorung uvulae, atque pharyngis nova descriptio, et delineatio. C. Pisarii, Bononiae. 